\title{
Los tratados de libre comercio impulsados por Estados Unidos en América Latina y la profundización del subdesarrollo
}

\author{
Arturo Huerta González*
}

\section{Resumen}

Este trabajo analiza la política comercial seguida por Estados Unidos (EUA) hacia América Latina y el Caribe ante el estancamiento generado en las negociaciones del Acuerdo de Libre Comercio para las Américas (ALCA), así como la aceptación de la mayoría de los países del área a las directrices fijadas por los EUA. Asimismo, se estudia la posición asumida sobre todo por Brasil y Argentina en contra del ALCA, además de la situación actual del Tratado de Libre Comercio de América del Norte (TLCAN) y la pérdida de competitividad que enfrenta México con China en el mercado estadounidense. A pesar de que la teoría predominante prioriza el libre comercio y el crecimiento hacia fuera como estrategia de crecimiento para los países del área, este trabajo se encamina a demostrar que dicha estrategia no representa la alternativa de crecimiento que estos países requieren debido a que no cuentan con las condiciones productivas y financieras para salir exitosos en dicho proceso.

Palabras clave: TLC, ALCA, TLCAN, competitividad, integración, vulnerabilidad.

\section{Introducción}

— ste trabajo analiza cómo los tratados de libre comercio que Estados Unidos (EUA)impulsa en América Latina (AL) imponen reglas de juego a su favor, pues le permiten aumentar su presencia en el área y expandir su mercado. Por su parte, los países latinoamericanos tienen poco poder de negociación frente a EUA $\mathrm{y}$, por lo tanto, terminan aceptando las condiciones que les imponen, tales como apertura comercial generalizada, bajos aranceles y las crecientes concesiones a EUA con la creencia de que ello les permitirá promover entrada de capitales y, así, tener condiciones de inversión y crecimiento en sus países.

\footnotetext{
*Profesor investigador de la Facultad de Economía de la Universidad Nacional Autónoma de México. Correo electrónico: ahuerta@servidor.unam.mx
} 
En estos tratados comerciales no se introducen medidas compensatorias que enmienden los diferenciales de productividad y competitividad; de igual forma, tampoco se incorpora el movimiento de mano de obra entre los países firmantes, ni las cuestiones laborales y ambientales, las cuales terminan actuando en detrimento de los latinoamericanos. Los gobiernos de AL no pueden condicionar la presencia de la inversión extranjera directa; además, no les pueden obligar a producir los bienes que el país requiere, sino que es decisión de las transnacionales ubicarse en los sectores de su interés.

Los países latinoamericanos no tienen condiciones productivas y financieras para salir exitosos, por esto se desindustrializan, van incrementado el desempleo y la integración con EUA y, en consecuencia, se profundiza el subdesarrollo y su vulnerabilidad.

\section{El motivo de Estados Unidos para impulsar tratados de libre comercio en América Latina y los métodos que emplea}

Las renegociaciones de la deuda externa en que ha caído nuestro país como el resto de América Latina con el Fondo Monetario Internacional (FMI), le ha permitido a esta institución imponer las políticas de liberalización económica (comercial y financiera), de disciplina fiscal, de estabilidad monetaria-cambiaria y de privatización, que emanan del llamado Consenso de Washington, es decir, del FMI y del Banco Mundial. Estas políticas van dirigidas a disminuir la presencia del Estado en la regulación de la actividad económica para dejar que ésta sea regulada y reestructurada por las libres fuerzas del mercado de economía abierta para así alcanzar mejores condiciones de crecimiento ante los problemas que las economías latinoamericanas enfrentaron ante la intervención creciente del Estado en la economía. De hecho, el reporte de la UNCTAD señala que "[... ] en América Latina la liberalización fue introducida como reacción al fracaso de la estrategia de desarrollo de sustitución de importaciones basada en la intervención gubernamental para generar rápido crecimiento e industrialización" (UNCTAD, 1995:73).

Desde esta perspectiva se han impulsado tratados de libre comercio (TLC) en América Latina y se han abolido las políticas proteccionistas, así como las de intervención y regulación del Estado en dichas economías. Se impulsa el libre comercio bajo la creencia de que ello propiciará mejor asignación de recursos y un proceso de competencia que se traducirá en mayor eficiencia y productividad y que permitirá a nuestros países crecer hacia el mercado externo con menores presiones macroeconómicas. El reporte de la UNCTAD afirma que "[...] un objetivo importante de las reformas estructurales fue la eficiencia y la productividad de los sectores de bienes comerciables. Se espera- 
ba rápido crecimiento de la productividad" (UNCTAD, 1995:82). Sin embargo, tales políticas de liberalización económica responden más a los intereses de EUA porque con ello pretende no sólo expandir su espacio de influencia en el área, sino asegurar la irreversibilidad de la instrumentación de la liberalización, desregulación y privatización económica, que le han redituado grandes frutos. El libre comercio le permitirá a EUA penetrar más fácilmente a los mercados de América Latina y el Caribe, dada su mayor productividad y competitividad en la gran mayoría de los productos comerciables respecto a éstos. De la misma manera, con ello desea afianzar la postura histórica de "América para los americanos" y, en consecuencia, frenar la presencia de Europa y Asia en esta área.

La estrategia de EUA hacia América Latina es avanzar con acuerdos bilaterales y no con acuerdos multilaterales ante los problemas que ha tenido en la Organización Mundial de Comercio (OMC), así como en el ALCA para imponer sus condiciones al resto de los países tercermundistas.

Estados Unidos, a través de impulsar los TLC bilaterales en América Latina y el Caribe, aprovecha e impone su posición de fuerza frente a los otros países al negociar por separado, para colocar condiciones a su favor que no puede lograrlas fácilmente a través de prácticas multilaterales de negociación; es decir, en los TLC que ha firmando y está negociando en el área latinoamericana, introduce posiciones a su favor que van mas allá de las negociaciones multilaterales establecidas en la OMC (Presser, 2004). En tales casos el TLC establece reglas que le permite a EUA ampliar los tratos preferenciales y la flexibilización a la entrada de sus productos e inversiones en el área, con ello expande sus mercados de productos e inversión y obtiene el control de sectores estratégicos que son de su interés, así como salvaguardar los beneficios de sus empresas transnacionales; todo lo anterior actúa en detrimento de los países firmantes o negociadores de dichos acuerdos. Con estos acuerdos bilaterales disminuye la participación y el control que los estados nacionales ejercen en la actividad económica; en consecuencia, se abren sectores estratégicos y de alta rentabilidad al capital internacional.

Por su parte, Brasil y Argentina se han opuesto a ciertas reglas y normas de comportamiento (entre ellas destacan las compras gubernamentales y el trato a la inversión extranjera) que el país norteamericano quiere establecer dentro del ALCA, por lo que este proyecto se ha frenado, representando ello una afrenta a los intereses hegemónicos de EUA. 
Ante el impasse y la dificultad de desbloquear las negociaciones, EUA ha optado por negociaciones bilaterales, para lo cual impulsa el TLC con los diferentes países del área con el fin de imponer fácilmente sus reglas de juego y utilizar dichos TLC como marco de referencia para la constitución del ALCA; los países que queden fuera de las negociaciones tendrán que sumarse más temprano que tarde a estos acuerdos bajo las reglas que ellos están estableciendo.

Estados Unidos ya ha firmado acuerdos de libre comercio con México, Chile, y está negociando con los países de Centroamérica y con los de la comunidad andina (Colombia, Perú, Ecuador y Bolivia). Venezuela, que es miembro de la comunidad andina, ha señalado que no se sumará a dicho acuerdo y ha presentado una propuesta alternativa de asociación latinoamericana junto con Cuba llamada Alternativa Bolivariana para América Latina y el Caribe (ALBA, 2003).

Al negociar EUA bilateralmente impone sus reglas, dado su gran poderío hegemónico, ante el cual país alguno no es capaz de anteponer sus intereses nacionales frente a los del gran imperio. Asimismo, el país norteamericano está colocando en estas negociaciones el acuerdo de inversiones que le fue rechazado en la OMC, lo que le permite un trato preferencial a sus inversiones en lo referente a áreas de ubicación y de protección ante cualquier pérdida de ganancia derivada de acciones de política económica que las pudieran afectar; así, tiene asegurada su inversión y su dominio económico en los países que se adhieren a dichos tratados. De tal forma, los TLC abarcan el libre flujo de mercancías y también incluyen el trato preferencial a la inversión extranjera; con este tipo de tratados se crean expectativas de que éstos son indispensables para el impulso de la actividad económica a través del crecimiento de exportaciones y los flujos de capital que ello propicia, y que permitirá a su vez disminuir la brecha entre desarrollados y subdesarrollados. ${ }^{1}$

En los TLC que EUA está estableciendo en América Latina y el Caribe no se contemplan políticas de compensación y de apoyo a infraestructura a favor de los menos desarrollados, tal como las que se establecieron en la Unión Europea donde los países más fuertes han instrumentado políticas compensatorias y de apoyo a los países más débiles. Cabe destacar que en el TLC que México firmó con Europa tampoco se

\footnotetext{
1 Ello se inserta en los postulados teóricos emanados del Consenso de Washington donde se dice que es mejor tener más mercado de economía abierta para propiciar el libre movimiento de mercancías y capitales para alcanzar mejores condiciones de eficiencia y crecimiento económico (véase Williamson, 2000).
} 
establecieron políticas compensatorias a favor del país latinoamericano, sino por el contrario se otorgaron grandes preferencias a los países europeos con el fin de que ellos lo aceptasen; con esto se evidenció que no hay diferencia entre los TLC que los países latinoamericanos establecieran con EUA y con los que se están firmando con Europa. Los países desarrollados no ceden a las aspiraciones de los países menos desarrollados de recibir tratos preferenciales encaminados a impulsar el desarrollo de estos últimos en la perspectiva de disminuir la diferencia entre ellos.

El avance de los TLC que la mayor parte de los países del área está teniendo con los EUA debilita las posiciones de Brasil y Argentina para alcanzar un ALCA diferente al deseado por EUA y que responda más a los propósitos de desarrollo económico más autónomo y autosustentado en el área. Estados Unidos está presionando a Argentina, aprovechando los problemas que tiene, para que se sume a un tratado de libre comercio con ellos y, así, aislar a Brasil y romper el MERCOSUR. Sin embargo, tal país no cede a las presiones y, por su parte, Brasil desarrolla una política de apoyo a Argentina para que mantenga su postura de oposición frente al ALCA.

\section{El motivo de los países de América Latina para impulsar y aceptar los TLC con EUA}

Los defensores en América Latina del libre comercio y de los flujos de inversión señalan que impulsar y aceptar los tratados de libre comercio permitirá tener acceso a la tecnología y ampliar los mercados, así como allegarse de fuentes de financiamiento externo. ${ }^{2}$ De ahí que mencionan que esta estrategia origina una mejor asignación de recursos e incrementa la eficiencia, lo que representa una mejor opción para desarrollar la industria y configurar un crecimiento sostenido en relación con el desempeño que tuvieron las políticas proteccionistas. ${ }^{3}$

La mayoría de los países de América Latina han firmado y están negociando tratados de libre comercio con Estados Unidos y otorgando concesiones al capital internacional, sobre todo para crear condiciones de confianza, rentabilidad y estabilidad a dicho capital, así como asegurar — a través de estos acuerdos comercia-

2 Igual planteamiento estuvo presente entre los defensores e impulsores del TLCAN para México (véase Glaessner y Oks, 1998).

${ }^{3}$ Existe oposición a las políticas proteccionistas por considerarlas que atentan sobre los niveles de productividad y competitividad necesarios para el desarrollo industrial, además por configurar precios monopólicos que recrudecen los niveles de concentración del ingreso y que atentan sobre la expansión de la demanda (véase Anderson, 2004 y Freud y Cajlar, 2004). 
les - la irreversibilidad de la apertura económica y las concesiones otorgadas con el fin de estimular flujos de capital hacia tales países, esperando con ello desarrollar la industria, generar empleo e impulsar la dinámica económica. Con los TLC con EUA, los países latinoamericanos pretenden no tanto allegarse del mercado estadounidense - pues éste siempre ha estado ahí y su acceso se ha tenido en forma limitada, lo cual se ha determinado por la baja capacidad productiva y competitiva existente- - sino buscan principalmente incentivar flujos de inversión a nuestros países y con ello poder incrementar la capacidad productiva; además, para financiar el pago del servicio de la deuda externa y evitar obstáculos externos al crecimiento. Indudablemente, es la carencia de recursos financieros por parte de los países de América Latina para cubrir sus obligaciones financieras externas, como para impulsar su dinámica económica, lo que los lleva a promover TLC con Estados Unidos para, así, atraer flujos de capital y hacer frente a sus carencias.

De igual manera, creen que las ventajas comparativas que cuentan en escasas ramas productivas, sobre todo en el sector primario, junto a las ventajas de localización podrán promover inversión extranjera directa (IED) para dinamizar sus economías e incrementar sus exportaciones y alcanzar una inserción dinámica en el mercado mundial.

A través del TLC con Estados Unidos, los países latinoamericanos esperan absorber los empleos que perdería dicho país al trasladar empresas hacia América Latina ante las posiciones competitivas que éstas ofrecen por los menores costos de mano de obra y de ciertos insumos productivos. ${ }^{4}$ Asimismo, consideran que la liberalización del comercio permite importar insumos productivos para abaratar costos de producción y, en consecuencia, para producir internamente bienes finales altamente competitivos en lugar de importarlos, mejorar la competitividad en la producción final y de esta manera incrementar las exportaciones, así como el desarrollo industrial.

La mayoría de los países ha negociado o está negociando un tratado de libre comercio con Estados Unidos porque creen que es mejor participar en el proceso de globalización que no estar en él; consideran que los beneficios del libre comercio son mayores a los costos que se derivan de ello; tales gobiernos ven en los TLC con Estados Unidos una oportunidad para el crecimiento

\footnotetext{
${ }^{4}$ Es generalizada la posición de la mayoría de los gobiernos latinoamericanos y del Caribe de impulsar los acuerdos comerciales bilaterales con EUA con el fin de obtener acceso privilegiado a dicho mercado, así como de beneficiarse del impulso al crecimiento y de generación de empleo que se derivaría de las inversiones extranjeras que tales acuerdos propiciarían (Bastos, 2004).
} 
de sus países. Por ello, señalan que no se le puede dar la espalda a la globalización debido a que parten de la posición de que dichos tratados comerciales ofrecen grandes oportunidades que se tienen que aprovechar, como si contasen con los niveles productivos y financieros necesarios para salir airosos de los procesos altamente competitivos que se configuran; además, los que actualmente están negociando TLC con Estados Unidos, como es la Comunidad Andina, ni siquiera estiman las consecuencias que estas políticas han originado en aquellos países como México, donde ya tiene once años de operar el tratado de libre comercio con Estados Unidos y Canadá.

Hay una divergencia de intereses detrás de los TLC, mientras EUA desea ampliar mercados a sus productos y a su inversión, los países del área pretenden con ello incrementar sus exportaciones al mercado estadounidense para dinamizar su industria, aminorar las presiones sobre el sector externo, así como promover inversiones para incrementar la productividad y alcanzar una mejor posición competitiva en el mercado internacional.

Por su parte, México ha venido abanderando la estrategia de liberalización económica en toda América Latina, impulsando los tratados de libre comercio y el ALCA. El gobierno mexicano difunde en todos los foros que el TLCAN ha sido exitoso, dado que ha incrementado las exportaciones de manufactura del país y ha promovido grandes flujos de capital y señalan que ésta debe ser la estrategia para el resto de los países de América Latina. Tal postura es más ideológica y de subordinación a los intereses de Estados Unidos, que al beneficio de los nacionales debido a que las mayores exportaciones y la mayor inversión extranjera que se ha propiciado como consecuencia de dicho TLC no se ha traducido en mayor desarrollo industrial, ni en mayor generación de empleo productivo, ni en crecimiento económico sostenido, sino — por el contrario- la economía mexicana hoy presenta mayores problemas productivos y financieros que antes de las políticas de apertura económica, lo que la ha colocado en un contexto de bajo crecimiento y de alta vulnerabilidad económica (véase CEPAL, 2004).

\section{Los TLC restringen la función de regulación y de promoción del Estado en la economía}

A través de los TLC, Estados Unidos impone reglas, leyes y políticas a su favor anulando el poder soberano de los gobiernos latinoamericanos para determinar y decidir sus políticas a favor de los productores nacionales para su desarrollo y 
para encarar el proceso de competencia que configura la economía abierta y la reducción de aranceles que establecen los TLC; EUA no otorga derechos especiales a los países latinoamericanos.

Se parte del postulado teórico de que al dejar las economías a las libres fuerzas del mercado con apertura externa, con la menor participación e intromisión estatal posible, se podrá alcanzar una mejor asignación de recursos a favor de la productividad para salir airosos del contexto competitivo configurado. ${ }^{5}$

Las concesiones que otorga EUA a los países del área son principalmente en sectores donde no representan peligro debido a su superioridad competitiva frente a sus adversarios. Las exportaciones manufactureras que América Latina destina a EUA son básicamente de alto componente importado con insumos de origen de dicho país; no obstante que el país norteamericano limita a los gobiernos latinoamericanos a que otorguen subsidios a los productores agrícolas e instrumenten políticas a favor de sus sectores productivos nacionales; por su parte, EUA mantiene políticas de subsidios a sus productores agrícolas y políticas proteccionistas en los sectores donde tiene productividad y competitividad menor que los países latinoamericanos, por lo que las perspectivas de ganar en dichos acuerdos no existen para estos últimos. En el caso de la agricultura, a los países en desarrollo que cuentan con menores niveles de productividad que EUA, se les da más plazos para eliminar subsidios, como si en realidad pudiesen en el plazo otorgado alcanzar la homologación de la productividad y competitividad para salir airosos del proceso competitivo.

Asimismo, las tarifas más altas que colocan los países latinoamericanos para compensar los diferenciales de productividad no los pone en una situación de protección frente a los productos agrícolas subsidiados provenientes de EUA, puesto que el producto importado sigue siendo más barato; con esto se evidencia el hecho de que las tarifas son insuficientes para estimular la producción nacional, la cual resulta insuficiente en la mayoría de los países del área para satisfacer el mercado interno.

\footnotetext{
5 El Reporte de la UNCTAD de 1999 resalta la creencia generalizada de que la rápida integración de la economía global crearía condiciones más favorables para el crecimiento en economías en desarrollo. Con la liberalización comercial y la mayor apertura al capital privado internacional se espera obtener mayor eficiencia, productividad y competitividad a través de la transferencia de tecnología, lo que colocaría a los países en desarrollo en la senda del crecimiento sustentable y resistente a los shocks externos (UNCTAD, 1999: 73).
} 
Los apoyos que la gran mayoría de los países latinoamericanos otorgan a su sector agrícola son escasos para incrementar la productividad y la producción para poder encarar la liberalización comercial de dichos productos. No cuentan con condiciones financieras y políticas fiscales (apoyos y subsidios), ni con condiciones técnicas para incrementar la productividad y su producción para enfrentar la competencia ante las importaciones. Si a ello se suma el tipo de cambio apreciado (que se deriva como consecuencia de la política de estabilización y de la entrada de capitales), se tiene menos posibilidad de sobrevivir a dicha competencia (Huerta, 2002) a pesar de las tarifas establecidas (permitidas) por los acuerdos alcanzados en el TLC y los pocos limitados apoyos internos que se pueden otorgar a este sector.

Los TLC que los países latinoamericanos han firmado y que otros están negociando con EUA - además de permitir el libre comercio de mercancías y disminuir significativamente los aranceles donde la gran mayoría de los productos quedan exentos de dicho pago — otorgan también trato preferencial a la inversión extranjera directa, eliminando los llamados requisitos de desempeño. De tal forma, a través de los TLC, el gobierno estadounidense exige que se otorgue a los inversionistas externos trato similar al que se da a los inversionistas nacionales. Así, la política económica instrumentada por los gobiernos latinoamericanos dentro de los TLC no puede hacer distingo alguno entre inversionistas nacionales y extranjeros. Al otorgar trato preferencial a la inversión extranjera, los gobiernos latinoamericanos se ven impedidos en instrumentar políticas económicas de subsidio y estímulo a favor de los productores nacionales. La inversión extranjera al recibir igual trato que la nacional, y al contar con mejores condiciones financieras y productivas que las nacionales, termina desplazando a estas últimas del mercado interno, por lo que terminan ocupando una posición dominante en la economía, y de ahí el proceso de extranjerización creciente de nuestras economías.

Los gobiernos locales no pueden aplicar medidas para regular el comportamiento de la IED; además, no pueden obligar a dicha inversión a consumir insumos, servicios y empleo nacionales, ni a destinar cierto porcentaje de su producción para el mercado externo con el fin de asegurar impactos positivos sobre el sector externo; asimismo, no se les puede exigir a orientar dicha inversión a determinadas industrias o regiones del país, ni imponerles que transfieran tecnología hacia el país latinoamericano, ni a desarrollarla internamente para impulsar la capacidad productiva y las condiciones competitivas nacionales; finalmente, tampoco se les condiciona a que permanezcan determinado tiempo en el país donde invierten. De 
tal forma, los inversionistas estadounidenses mantienen su superioridad tecnológica y financiera con relación a los productores de América Latina y el Caribe, lo que les permite acentuar su poder monopólico y desplazar a los nacionales de los mercados locales; esto no sólo aumenta las presiones sobre el sector externo, sino que atenta sobre la dinámica de acumulación y de capitalización de los productores nacionales.

Si Estados Unidos considera que las leyes y las políticas económicas de los países firmantes de los TLC actúan en detrimento de los intereses de sus empresas — ya sea porque éstas operen en el territorio estadounidense o en los países donde se han establecido - las cuestiona y exige su anulación. De hecho, si una empresa transnacional se siente afectada por las reglamentaciones existentes en el país donde opera (dentro de los TLC) puede llevar al gobierno en cuestión a tribunales internacionales para ser indemnizada. Los gobiernos latinoamericanos, ante el temor de recibir sanciones o represalias por parte de Estados Unidos o de los organismos internacionales controlados por dicho país, terminan sometiéndose y subordinándose a las reglas impuestas por éstos.

Asimismo, dentro de los TLC, los gobiernos locales están obligados a abrir todos sus sectores económicos, productivos, financieros, servicios y comerciales a la inversión extranjera, acelerando con ello el proceso de extranjerización, dado que tales inversiones cuentan con mejores condiciones financieras y tecnológicas para desplazar de los sectores económicos más rentables de la economía a los inversionistas nacionales. ${ }^{6}$

Se les otorgan grandes concesiones a las inversiones externas y no se les impone obligaciones y regulación alguna a dichos flujos de capital, ni condicionan su entrada al cumplimiento de obligaciones fijadas por los gobiernos nacionales. Ello explica por qué las empresas transnacionales trabajan con bajo valor agregado nacional y generan, en consecuencia, impactos negativos sobre el sector externo; y también por qué dichos flujos de inversión no se han traducido en mayor desarrollo industrial, ni en mayor generación de empleo en nuestros países. De tal forma, las empresas transnacionales que operan en el área latinoamericana originan déficit de comercio exterior y crecientes remesas de recursos al exterior, así como pocos efectos multiplicadores internos. Es tal el poder que adquieren estas empresas que debilitan

\footnotetext{
${ }^{6}$ Nos dice el Reporte de la UNCTAD del 2002 que "Los países en desarrollo han facilitado las operaciones de las empresas transnacionales en su territorio, mientras que los países industrializados han facilitado el acceso a sus mercados de las importaciones de bienes que contiene insumos procedentes de sus propias economías y que están fabricados en plantas de montaje de estas empresas transnacionales" (Trade Development Report 2000, UNCTAD, p. 64).
} 
la posición de los gobiernos locales para controlarlas y para que su funcionamiento responda a las necesidades nacionales de generación de empleo, de incremento del valor agregado nacional de su producción y de desarrollo económico.

El desempeño de las empresas transnacionales no favorece a las economías donde se establece, sino que las perjudica debido a que desplaza a la producción nacional del mercado interno, aumenta el déficit de cuenta corriente de balanza de pagos y, además, presiona para que la política económica responda a sus exigencias a costa de que se releguen las demandas de los nacionales (Huerta, 2004:178-180).

Estados Unidos condiciona los TLC, a los cuales les exige que se les protejan los derechos de propiedad intelectual; esto les permite tener el control monopólico sobre el desarrollo tecnológico y sus patentes, impidiendo y sancionando cualquier práctica de piratería que pueda ser llevada a cabo por nacionales, lo que les resulta a éstos más difícil y costoso cualquier avance tecnológico; es decir, las vías de desarrollo tecnológico alcanzadas en décadas pasadas por países como Japón y los del Sudeste Asiático - y en los últimos años en China e India - a través de la piratería (copia e imitación de tecnología) les queda vedada a los países latinoamericanos con los TLC que el país norteamericano está imponiendo en la región.

A pesar de que el TLCAN contempla mecanismos de solución de controversias para resolver prácticas desleales de comercio, éstas siguen operando por parte de los Estados Unidos sin que sea sancionado, lo que evidencia que es la gran potencia la que determina las reglas de juego a su favor, sin tener los países menos desarrollados capacidad de hacer valer su posición.

En los TLC que se han firmado o están negociando con los países latinoamericanos, las cuestiones laborales y ambientales no están incorporadas; tampoco se incorpora la movilidad de trabajadores hacia Estados Unidos, no se contempla la situación laboral por la que atraviesan los inmigrantes latinoamericanos en dicho país, ni se incorporan los derechos laborales para que los trabajadores del área alcancen los derechos existentes en EUA (Puyana y González, 2004).

Los gobiernos de los países latinoamericanos no consideran — o desestiman el hecho- que dichos tratados les impiden instrumentar políticas económicas a favor de sus productores nacionales y que, por lo tanto, los deja en una situación indefen- 
sa frente a los productos importados, los cuales terminan desplazando a los productores nacionales. La mayoría de los gobiernos latinoamericanos, en la perspectiva de ser bien vistos por Estados Unidos, acepta las reglas establecidas por este país, lo que genera una mayor apertura, liberalización y desregulación de todos sus sectores, sin duda el país norteamericano sale ganando en dicho proceso.

Los gobiernos latinoamericanos se preocupan sólo por su gestión porque de esa manera promueven capitales y alcanzan un crecimiento de corto plazo (derivado de los flujos de capital provenientes por los activos que puedan vender), sin considerar los alcances de tales políticas y las concesiones otorgadas al gran capital internacional que generan sobre nuestras economías. Con la liberalización económica y los TLC, los gobiernos de América Latina se ven impedidos en instrumentar políticas de desarrollo nacional, por lo que se condenan al atraso y a que su economía esté determinada en gran medida por factores externos, sean exportaciones y/o entrada de capitales. No estiman que con la liberalización comercial y la reducción de los aranceles se abre paso a todos los productos, lo que en consecuencia éstos desplazan a la producción nacional; esto da como resultado el déficit de comercio exterior y el rompimiento de las cadenas productivas y acelerados procesos de desindustrialización.

\section{La disputa de Brasil y Argentina frente a Estados Unidos en torno al ALCA}

En las negociaciones del ALCA, no se dio la oportunidad de negociar en bloque, donde América Latina participara en forma unificada y comprometida en anteponer los intereses de la región frente a los EUA. Brasil, Venezuela y Argentina son los únicos países que tienen posturas más consecuentes y también se han contrapunteado frente a los intereses de Estados Unidos, lo que ocasiona estancar dicho proceso de negociación. Brasil y Argentina se han opuesto a las exigencias de Estados Unidos de introducir en el ALCA los servicios, las inversiones, las compras gubernamentales y la propiedad intelectual debido a que consideran que ello involucra "pérdida de autonomía nacional para ejecutar políticas de desarrollo", concernientes a políticas industriales, fiscales y cambiaria, entre otras (Bastos, 2004).

Desafortunadamente no hay posiciones homogéneas y de consenso entre los países latinoamericanos para hacer un frente común a Estados Unidos. Países como México y Chile que tienen TLC con EUA y que le han otorgado grandes concesiones, colocan en una situación de desventaja competitiva al resto de los países de Améri- 
ca Latina para negociar el ALCA frente al país norteamericano, pues éste pretende extender los acuerdos ya alcanzados con México y Chile hacia el resto de los países.

El TLCAN ha pasado a ser marco de referencia para generalizarlo en el ALCA, donde existe apertura y liberalización y desregulación de las inversiones, así como del sector servicios, la apertura y licitación de las compras gubernamentales, y el respeto a la propiedad intelectual; estas posiciones no son aceptadas por países como Brasil y Argentina (Bastos, 2004).

Además, el país norteamericano asume una postura de defensa de mantener barreras a los llamados bienes "sensibles" (aquéllos en los que tiene una productividad menor a la de sus adversarios) y desea mantener subsidios en los productos agrícolas, así como mantener normas técnicas y fitosanitarias. En cambio, Argentina y Brasil quieren tener acceso a ese mercado de bienes "sensibles" de EUA y se pronuncian para que se coloquen límites al uso de subsidios, así como a las normas técnicas y fitosanitarias, con el fin de que no se ponga límites al acceso de productos latinoamericanos hacia el mercado de Estados Unidos. Asimismo, estos países latinoamericanos mantienen una postura defensiva a favor de mantener barreras en los mercados industriales y de servicios que son "sensibles" para América Latina; es decir, proteger a los bienes que no tienen competitividad y no abrir compras gubernamentales, así como mantener la autonomía de su política económica (Bastos, 2004).

Mientras Estados Unidos divide a los países latinoamericanos para así debilitar la posición negociadora de éstos e imponer, por lo tanto, la propia, Brasil trata por su parte de fortalecer el MERCOSUR y aplicarlo con otros países del área; de igual forma, bajo la iniciativa de este país a fines de 2004 se ha fundado la Comunidad de Naciones de América del Sur donde se pretende que el ALCA sea discutido por dicha Comunidad con el gobierno de Bush. Con ello se aspira a tener poder de negociación, no sólo frente al ALCA para frenar la posición hegemónica de EUA, sino también en relación con los acreedores internacionales para negociar la deuda externa.

\section{La apertura comercial, la falta de competitividad y los mayores requerimientos de entrada de capitales}

En los acuerdos bilaterales predominan negociaciones asimétricas donde la posición hegemónica de Estados Unidos es la dominante y, por ello, impone sus reglas. Esto trae como consecuencia que en vez de disminuir la heterogeneidad 
existente entre tal país y los países latinoamericanos, ésta se profundiza, pues estos TLC atentan sobre la esfera productiva de estos últimos, además, incrementan las presiones sobre el sector externo, lo que los coloca en una posición de alta vulnerabilidad externa.

Si los acuerdos multilaterales alcanzados en la Organización Mundial de Comercio (OMC) no han actuado a favor de los países en desarrollo para que los flujos comerciales y financieros impulsen su dinámica económica y disminuya la brecha con los países industrializados, mucho menos se alcanzarán mejores condiciones comerciales y de inversión para reducir las asimetrías mediante los TLC que han firmado los países latinoamericanos y otros están negociando con EUA. Se sigue en un proceso de maximización de pérdidas y minimización de ganancias en dichos acuerdos internacionales; en cambio, EUA a través de los acuerdos multilaterales y sobre todo en los acuerdos bilaterales, fortalece su posición de negociación y sus ganancias. Para reducir las asimetrías existentes, se requeriría que EUA tomase posiciones unilaterales a favor de los países latinoamericanos, situación que está muy lejos de darse, pues iría contra su lógica de expansión y dominio.

Sin duda los países latinoamericanos terminan perdiendo en el proceso de negociación que permite el libre flujo de mercancías e inversiones porque no cuenta con los niveles de productividad y competitividad que tienen los productos provenientes de EUA y del resto de países desarrollados y del sudeste asiático, por lo que los productos importados terminan desplazando a la producción nacional.

El contexto de libre comercio - ya sea con el país norteamericano así como con otros países desarrollados y el hecho de estar insertos en la OMC — nos coloca en desventaja competitiva con empresas que son tecnológica, productiva y financieramente superiores a las nuestras. Los productos donde se tiene ventajas (que son los menos) no reciben trato preferencial de libre acceso al mercado estadounidense.

La apertura comercial y la disminución y desaparición de aranceles que trae consigo los TLC nos coloca en igualdad de circunstancias con los productores estadounidenses y de otros países del mundo, como si en el plazo determinado para la homologación, reducción y eliminación de aranceles a la importación, pudiésemos alcanzar los niveles de productividad y competitividad para encarar el proceso de competencia que configuran los TLC y la apertura comercial. Esto lleva a la gran mayoría de los países latinoamericanos a comprar del exterior más que 
lo que exportan; de tal forma que la búsqueda de mayor acceso al mercado de EUA para dinamizar la producción no se da por los TLC ante nuestra falta de competitividad.

La mayor competencia que países como México han venido enfrentando, como consecuencia del contexto de libre comercio en que operan, no se ha traducido en mayores niveles de productividad y eficiencia en su aparato productivo que le permita aumentar su capacidad exportadora y el valor agregado nacional en éstas. La brecha tecnológica con respecto a EUA no se ha reducido, sino - por el contrario - ésta se ha incrementado, pues el TLCAN y la política que le acompaña impiden instrumentar políticas de apoyo a los productores industriales nacionales.

La política de apertura comercial, más que contribuir a la generación de riqueza productiva para potenciar el crecimiento de la economía, está destruyendo cadenas productivas, y atentando sobre la dinámica de acumulación, lo que frena el crecimiento de la inversión y compromete el crecimiento endógeno de la economía y del empleo. Por su parte, la liberalización del comercio exterior ha llevado a aumentar el déficit de comercio exterior y a depender en forma creciente de los flujos de capital. ${ }^{7}$

Cabe señalar que la política de apertura comercial es acompañada de la liberalización financiera para estimular los flujos de capital necesarios para financiar el déficit externo y mantener estable la moneda. Para asegurar entrada de capitales para financiar el déficit externo y evitar que éste frene la actividad económica y desestabilice el tipo de cambio, las economías del área se ven obligadas a ofrecer activos rentables al capital internacional. De ahí el porqué la apertura comercial y financiera van acompañadas de las políticas de estabilización y de mayor endeudamiento externo, de mayor privatización y extranjerización de las economías latinoamericanas, disminuyendo con ello el margen de libertad para tener políticas económicas a favor de crecimiento económico.

Asimismo, la liberalización financiera lleva a las economías a caer en contextos de alta vulnerabilidad externa, pues al permitir el libre flujo de capitales aquéllas pasan a estar sujetas a las acciones especulativas que se derivan de ello, lo cual

\footnotetext{
Tal situación no es sólo de México, sino de la gran mayoría de las economías en desarrollado. La UNCTAD en su Reporte del 2002 nos dice "[...] muchos países en desarrollo, en particular los que habían acometido una amplia y rápida liberalización del comercio y de la balanza de cuenta de capitales, experimentaron al tiempo un deterioro de su balanza de comercio exterior y disminución de sus tasas de crecimiento económico" (Trade Development Report 2002, UNCTAD, p. 177).
} 
obliga a los países a trabajar con políticas monetarias y fiscales restrictivas para asegurar la estabilidad de la moneda, eliminar incertidumbre y evitar prácticas especulativas. Es por ello que se han tenido que establecer políticas macroeconómicas dirigidas a crear las condiciones de confianza, estabilidad y rentabilidad para atraer a dichos capitales y mantenerlos en el país.

De tal forma, el TLCAN no sólo ha impulsado el flujo de mercancías entre México y Estados Unidos, sino también el flujo de capitales. Estos flujos crecieron en la década de los noventa (con excepción de 1994-95, año de crisis) tanto por las políticas de estabilización, como porque han estado ligados a las exportaciones, así como al proceso de privatización y extranjerización. Estas políticas promueven los flujos de capital que son importantes para el financiamiento del déficit del sector externo para incrementar reservas internacionales y para estabilizar el tipo de cambio que exige el proceso de liberalización financiera, el cual termina apreciándose. Los capitales que fluyeron a la economía mexicana en la primera parte de la década de los años noventa fueron sobre todo inversión de cartera. De 1996 a la fecha, los mayores flujos de inversión se han dado por cambio patrimonial. El flujo de capitales se ha canalizado al sector exportador de alto coeficiente importado, así como al sector comercio y de servicios y a la adquisición de empresas ya existentes sin generar efectos positivos sobre la esfera productiva y el sector externo.

Los grandes flujos de mercancías y de capitales propiciados por el TLCAN no se han traducido en mayor capacidad productiva que permita avanzar en la sustitución de importaciones y aumentar el valor agregado nacional de las exportaciones, por lo que no se ha generado efectos multiplicadores internos sobre empleo y el ingreso de empresas e individuos en la perspectiva de cimentar las bases reales para el crecimiento económico, como para disminuir la brecha existente con los países desarrollados que dicha estrategia de crecimiento prometió; por el contrario, tales flujos de mercancías y capitales han atentado no sólo sobre la esfera productiva, sino también sobre las variables macroeconómicas necesarias para el crecimiento sostenido de la economía. Al déficit de comercio exterior hay que sumarle las transferencias de recursos al exterior que se derivan de la entrada de capitales, tanto por concepto de obligaciones financieras que se contraen por dicho capital, como por los pagos que se realizan por concepto de remisión de utilidades y pago de tecnología, lo que aumenta el déficit de cuenta corriente y los requerimientos de entrada de capitales para hacerle frente. 
Indudablemente el problema es que las presiones sobre el sector externo están latentes en la mayoría de las economías del área, y éstas no tienen asegurado un flujo permanente y creciente de capitales. De igual forma, por más que la política económica se dirige a crear condiciones de rentabilidad y confianza - a través de políticas de estabilización monetaria - para atraer capital externo no se tiene asegurado el flujo permanente de tales capitales, pues éstos no dependen tanto de la política de estabilización, sino principalmente están en función del ritmo de crecimiento de las exportaciones, como de las condiciones de rentabilidad ofrecidas por la economía, ya sean activos y empresas susceptibles de ser vendidas y/o inversiones atractivas. Esto se desvanece tanto por la menor actividad económica de EUA como por la pérdida de competitividad, además por los problemas de bajo crecimiento e incapacidad de pago derivado de la política económica imperante. Hay que considerar que los flujos comerciales y financieros van aparejados, por lo que al caer los primeros, caen los segundos, y caerán más al agotarse y limitarse el proceso de privatización. Lo anterior comprometerá el financiamiento del déficit externo, así como la estabilidad del tipo de cambio y la propia operatividad de la liberalización económica.

Los requerimientos crecientes de entrada de capitales y la liberalización financiera impiden a los gobiernos tener política macroeconómica a favor de la inversión productiva y del crecimiento del mercado interno ante el temor de que ello sea inflacionario. El problema se agudiza debido a que las políticas monetarias y fiscales restrictivas establecidas para evitar presiones inflacionarias recrudecen los problemas de productividad y competitividad de la producción nacional frente a importaciones; además, actúan contra los niveles de rentabilidad de la esfera productiva y de la inversión, por lo que no se puede hacer frente al contexto de economía abierta en que nos coloca los TLC. Tales países pasan a estar en el peor de los mundos posibles, pues ni pueden crecer en torno al mercado interno, ni tienen condiciones para crecer hacia el mercado externo.

Nuestros gobiernos, en lugar de preocuparse de los TLC y en promover flujos de capital, deben poner énfasis en el impulso a la esfera productiva nacional, pues ésta - más que favorecerse por los TLC — sale perjudicada, por lo que otras deben ser las políticas predominantes. 


\section{EI TLCAN ha incrementado la integración de la economía mexicana con la estadounidense}

El TLCAN entre México-EUA-Canadá ha incrementado la integración económica del primero con el segundo. La liberalización económica, junto a los acuerdos signados en el TLCAN, y la política de estabilización que acompaña dicho proceso han incrementado más los flujos comerciales y financieros entre la economía mexicana con la estadounidense, pasando la primera a ser más dependiente y vulnerable al comportamiento de la segunda. El predominio de las políticas monetarias y fiscales contraccionistas — que restringen el crecimiento del mercado interno - hace depender la dinámica económica de México del comportamiento de sus exportaciones, como de los flujos de capital, lo que a su vez depende del desempeño de la economía de EUA, quien es nuestro principal socio comercial. Ello ha llevado a que la economía mexicana acompañe el ciclo económico observado en la economía estadounidense.

El TLCAN entró en vigor el $1^{\circ}$. de enero de 1994 y vino acompañado de una fuerte dinámica de la economía de EUA en dicho periodo hasta el 2000, lo que repercutió en un flujo sostenido de bienes y servicios, así como de capitales ligados a exportaciones, como a la búsqueda de opciones de inversión en la adquisición de activos y empresas rentables.

La dinámica de la economía estadounidense y su creciente demanda por importaciones permitió a México salir fácilmente de su crisis manifiesta a fines de 1994. Junto a ello, la devaluación derivada de la crisis configuró precios relativos que contribuyeron favorablemente al crecimiento de exportaciones porque mejoró la competitividad de la producción de México y abarató los activos y empresas nacionales para estimular los flujos de inversión extranjera para la adquisición de dichos activos. De tal forma, la dinámica estadounidense y el consecuente incremento de exportaciones de México le permitieron a éste crecer un 5\% promedio anual de 1996 al 2000; sin embargo, el bajo valor agregado nacional de las exportaciones originó que este crecimiento no irradiase al conjunto de la economía sino que fuese acompañado de un mayor crecimiento de importaciones y presiones sobre la balanza de comercio exterior.

Los altos niveles de apertura comercial, es decir, las importaciones más exportaciones en relación con el PIB pasaron de ser 31\% en promedio en el periodo 19891993, a ser 71.5\% en 2001-2003 (Ruiz, 2004). Ello refleja las consecuencias de la apertura económica y la política que le acompaña, así como el alto grado de 
complementariedad alcanzado entre la industria estadounidense y la mexicana, además de la alta vulnerabilidad externa en que la economía nacional ha caído. Los flujos comerciales entre EUA y México ya venían creciendo desde antes del TLCAN; este tratado sólo vino a consolidar dicho proceso.

El siguiente cuadro refleja que en la década previa (1984-93) al TLCAN, las exportaciones de México hacia EUA crecían más que el crecimiento mostrado de 1994 a 2003. El TLC no viene a potenciar un mayor acceso nuestro a dicho mercado, ni son las barreras y aranceles existentes un impedimento al acceso al mercado estadounidense, sino nuestra falta de capacidad productiva y competitiva nacional, lo cual el TLC no resuelve.

\begin{tabular}{|l|c|c|}
\hline \multicolumn{3}{|c|}{ Tasas de crecimiento promedio anual } \\
\hline & $\mathbf{1 9 8 4 - 9 3}$ & $\mathbf{1 9 9 4 - 2 0 0 3}$ \\
\hline Exportaciones sin petróleo & 15.1 & 11.9 \\
\hline Exportaciones de maquila & 18.0 & 13.0 \\
\hline Export. Manufactureras sin maquila & 15.0 & 11.0 \\
\hline
\end{tabular}

Fuente: Secretaría de Economía, tomado de Antonio Gazol, "En torno al agotamiento el TLCAN", en Economía Informa, No. 327, junio, 2004

A pesar de que el gobierno mexicano es el que ha firmado más TLC que cualquier otro país, ello no se ha traducido en mayor diversificación de su comercio exterior; éste se ha concentrado más hacia la economía estadounidense. Las exportaciones de México hacia Estados Unidos en 2003 fueron el 88.8\% del total, en cambio las importaciones provenientes de dicha economía representaron el 61.8\%.

\begin{tabular}{|c|c|c|}
\hline \multicolumn{2}{|c|}{ Exportaciones de México a Estados Unidos } \\
\hline & Valor & \% \\
\hline 1990 & 32.3 & 79.4 \\
\hline 1995 & 66.6 & 83.8 \\
\hline 2000 & 149.0 & 89.5 \\
\hline
\end{tabular}

Fuente: CEPAL, Oportunidades y retos económicos de China para México y Centroamérica, 27, septiembre, 2004

No obstante la existencia de un TLC de México con los países europeos, ello no ha revertido la tendencia decreciente en el flujo comercial entre estos socios. Las exportaciones de México hacia Europa en 1990 representaban el 13.2\% del total, 
en 2003 sólo fueron el 3.9\%; por su parte, las importaciones de México provenientes de Europa pasaron de $16.6 \%$ al 9\% durante el mismo periodo (Calderón, 2004).

Los flujos comerciales entre México y Estados Unidos han llevado a que este último país, de ser superavitario en 1993 por 1.1 mil millones de dólares, pasara con el TLCAN a ser deficitario, alcanzando en 2003 un déficit comercial de 41.8 mil millones de dólares.

\begin{tabular}{|lc|cc|} 
Irportaciones de EU & $\mathbf{1 9 9 3}$ & $\mathbf{2 0 0 0}$ & $\mathbf{2 0 0 3}$ \\
$\begin{array}{l}\text { proveruentes de México } \\
\begin{array}{l}\text { Exportaciones de EU } \\
\text { hacia Mérios }\end{array}\end{array}$ & 49.4 & 136.8 & 1390 \\
\hline Saldo & 41.5 & 111.2 & 97.2 \\
\hline
\end{tabular}

Fuente: Blecker, R., "The North American Economies after NAFTA: A Critical Appraisal", International Journal of Political Economy, 2005

El superávit obtenido por México en su comercio con Estados Unidos se explica sobre todo por las exportaciones de maquila, las cuales se caracterizan por tener un valor agregado nacional de $2 \%$ y un componente importado de $98 \%$; es decir, sólo incorporan mano de obra; más que exportaciones de mercancías es exportación de servicios de mano de obra, por lo que su dinámica no genera efectos multiplicadores importantes en la dinámica económica nacional. El crecimiento de estas exportaciones va acompañado de igual crecimiento de importaciones; la derrama salarial que originan tales exportaciones tampoco tiene un impacto significativo sobre la demanda nacional debido a que el consumo en la frontera norte (donde están establecidas el mayor número de maquiladoras) se realiza en el otro lado de la frontera y tiene un alto componente importado.

Dicho superávit comercial es generado porque las empresas transnacionales exportadoras triangulan su comercio; importan insumos de Asia para procesarlos internamente y de aquí exportarlos hacia EUA. De ahí que el superávit mostrado con Estados Unidos lo explica el déficit comercial que México muestra con el resto del mundo, el cual es sobre todo con China y otros países asiáticos. 
Los tratados de libre comercio impulsados por Estados Unidos en

América Latina y la profundización del subdesarrollo

\begin{tabular}{|c|c|c|c|c|c|c|c|}
\hline & $x$ & $\begin{array}{c}\text { Comercio } \\
\text { TLCAN } \\
\mathbf{M}\end{array}$ & $X-M$ & $\begin{array}{l}\text { Balanza } \\
\text { maquila }\end{array}$ & $\begin{array}{c}\text { Balana TLC } \\
\text { sinmaquila }\end{array}$ & $\begin{array}{c}\text { Balarra } \\
\text { resto } \\
\text { mindo }\end{array}$ & $\begin{array}{c}\text { Balanga } \\
\text { comercial }\end{array}$ \\
\hline $\begin{array}{l}1994 \\
2000 \\
2003\end{array}$ & $\begin{array}{l}53.4 \\
1512 \\
1498\end{array}$ & $\begin{array}{l}58.6 \\
1318 \\
1102\end{array}$ & $\begin{array}{l}-5.2 \\
25.3 \\
39.7\end{array}$ & $\begin{array}{l}58 \\
19.3 \\
18.3\end{array}$ & $\begin{array}{c}-110 \\
6.0 \\
21.3\end{array}$ & $\begin{array}{l}-13.3 \\
-35.2 \\
-45.3\end{array}$ & $\begin{array}{l}-18.5 \\
-9.9 \\
-56\end{array}$ \\
\hline
\end{tabular}

Fuente: Estadísticas de Comercio Exterior, INEGI, tomado de Pablo Ruiz N.,

"El TLCAN y la balanza comercial de México", en Economía Informa, No. 327, junio, 2004

El déficit con el resto del mundo es superior al superávit alcanzado con Estados Unidos y Canadá dando por resultado un déficit comercial; cabe señalar que otro elemento que explica el superávit comercial con Estados Unidos son las exportaciones petroleras.

Si se sustrae el superávit de las maquilas y las exportaciones petroleras, se presenta un déficit comercial de la economía mexicana mucho mayor como resultado de los fuertes rezagos productivos, del rompimiento de cadenas productivas y de su falta de competitividad; es decir, es la venta de servicios de mano de obra barata (presente en las exportaciones de maquila) y de las exportaciones petroleras, lo que reduce el déficit de comercio exterior de México.

El crecimiento de la economía nacional se frenó de 2001 a 2003, una vez que la economía estadounidense dejó de crecer porque contrajo el crecimiento de las exportaciones de México a dicho país.

Después de que de 1994 a 2000 crecieron las exportaciones de mercancías hacia EUA en $18.2 \%$ promedio anual, tuvieron un crecimiento de $0.3 \%$ promedio anual de 2000 a 2003 y, excluido el petróleo, tuvieron una caída de 0.7\% promedio anual (Gazol, 2004). Las presiones que esto originó sobre el sector externo de México obligaron a las autoridades mexicanas a contraer la actividad económica para así reducir importaciones y evitar mayor déficit comercial externo que pudiese desestabilizar el tipo de cambio y afectar al capital financiero internacional ubicado en el país. De tal forma, la economía nacional ni mostró crecimiento de exportaciones, ni hacia el mercado interno, por lo que tuvo un crecimiento promedio anual de 0.6\% de 2001 a 2003.

El efecto del TLCAN sobre el empleo ha sido negativo, pues la creación de empleo de la maquila de 1993 a 2003 fue de 520031 trabajos; es decir, se pasó de 542074 a 1062105 empleos en dicha industria (Blecker, 2004). A pesar de 
haberse duplicado dicha generación de empleos en 10 años en tal sector, esto no contrarrestó el desempleo generado en la industria manufacturera (donde se incluye el empleo generado por las exportaciones manufactureras de no maquila), el cual se dio por el cierre y reestructuración de empresas como consecuencia de su falta de competitividad frente al gran crecimiento de importaciones que se deriva del contexto de apertura comercial y de la apreciación del tipo de cambio.

El aumento del desempleo, junto al menor crecimiento del PIB per cápita y a la caída de los salarios reales, ha empeorado la distribución del ingreso. El ingreso de los productores y trabajadores nacionales se reduce como consecuencia de la pérdida de competitividad frente a importaciones, por lo que se realiza una transferencia de ingreso a favor de los productores externos que nos abastecen de productos.

La falta de oportunidades de empleo y los bajos salarios existentes han incrementado la emigración de trabajadores hacia EUA en búsqueda de mejores oportunidades de empleo; se calcula un flujo neto de más de 500 mil indocumentados mexicanos que ingresan por año al país norteamericano.

\section{El desplazamiento de México del mercado estadounidense y los límites del crecimiento hacia afuera}

La caída de las exportaciones de México hacia Estados Unidos en los últimos años no sólo ha sido por el menor crecimiento económico del país norteamericano, sino por la creciente presencia de China en dicho mercado dada su mejor posición competitiva y por el hecho de que pasó a ser miembro de la OMC. En 2003 observamos la pérdida de competitividad de las exportaciones mexicanas en el mercado estadounidense, pues el crecimiento de las importaciones de este país fue de $8.5 \%$ con respecto al 2002 y en cambio las provenientes de México cayeron en $1.9 \%$ (Gazol, 2004).

La gran posición competitiva de China, no sólo por los menores salarios sino por el avance en el desarrollo tecnológico que está alcanzando, le ha permitido incrementar su participación en el mercado mundial. En el caso de su participación en el mercado de EU, ha pasado a desplazar a México del segundo lugar como socio comercial de este país, siendo que en 1990 las exportaciones chinas ocupaban el lugar 32 de las importaciones realizadas por Estados Unidos (CEPAL, 2004). 
En el caso de las exportaciones de autopartes de México a EUA en el periodo 1990 a 2003 aumentaron en 16.5\% promedio anual; en cambio las exportaciones chinas a dicho mercado lo hicieron en 37.6\% promedio anual para el mismo periodo (CEPAL, 2004).

Por lo que respecta a las exportaciones de productos electrónicos de China, éstas representaban en 1990 el 3.3\% de las importaciones que de esos productos realizaba Estados Unidos, y en el 2003 pasaron a ser el 18.26\% de ese total; mientras que las exportaciones de México de esos productos en 1990 representaban el 13.3\% del total de las importaciones de Estados Unidos de esos productos y en 2003 pasaron a ocupar el 20\%; es decir, en tanto las exportaciones de productos electrónicos de China aumentaron 15 puntos porcentuales en el total importado por Estados Unidos en dicho periodo, las exportaciones en México aumentaron menos de 7 puntos porcentuales (CEPAL, 2004).

En el mercado de computadoras, las empresas transnacionales ubicadas en México satisfacían en 2000 el 14.34\% del mercado de EUA y por su parte las exportaciones chinas abastecían sólo el $4.23 \%$. En el 2003, las exportaciones provenientes de México abastecían el $10.87 \%$ de dicho mercado y, en cambio, las exportaciones de China abastecían el 28.19\% (CEPAL, 2004).

Ante la gran trayectoria que China ha experimentado en los últimos 25 años, nuestro país no tiene nada que hacer frente a él para recuperar o mantener su posición en el mercado estadounidense. De 1978 a 2002 la tasa de crecimiento promedio anual del PIB per cápita de China fue de 8\% (CEPAL, 2004); en cambio en México entre 1982 y 2003 creció a una tasa promedio anual de sólo $0.6 \%$, ni en el periodo de mayor crecimiento de México, llega a la mitad de crecimiento alcanzada en China, pues de 1940 a 1981 el crecimiento per cápita verificado en nuestro país fue de 3.2\% (Casar y Ros, 2004).

La inversión como porcentaje del PIB en China es de $40.24 \%$ en 2002 y en ese mismo año el crédito interno del sector bancario al sector privado representó el 137\% del PIB (CEPAL, 2004); en cambio en México dicha proporción fue de 15\% y la inversión en relación con el PIB en 2003 fue de 19.0\%, por lo que no tiene condición alguna de recuperar su posición competitiva en el mercado estadounidense frente a China.

El crecimiento de exportaciones no puede constituirse en el motor del crecimiento de la economía mexicana, dado el tipo de exportaciones manufactureras que se realizan, las cuales tienen un bajo valor agregado nacional. Cada vez hay un ma- 
yor número de países que exporta tal tipo de bienes, dado que aportan lo barato de su mano de obra, lo que hace que dicho mercado sea altamente competitivo, pues son muchos países los que producen tal tipo de productos. ${ }^{8}$ Asimismo, la mayoría de esos bienes no enfrenta una alta elasticidad del ingreso, por lo que no son los más dinámicos de los mercados internacionales y, además, no puede generar un gran arrastre multiplicador interno que pueda beneficiar al conjunto de la economía nacional y propiciar efectos positivos sobre el sector externo que puedan aliviar la restricción externa al crecimiento.

El mercado de exportaciones manufactureras de bienes de alto valor agregado nacional es el más dinámico en los mercados internacionales, por lo que si México y América Latina desean tener una participación activa y dinámica en dichos mercados, requieren de desarrollo tecnológico e impulsar la industria manufacturera, para lo cual se exige de políticas macroeconómicas para tal fin. El problema es que los TLC y el contexto de liberalización financiera no lo permiten debido a que restringen el manejo de la política monetaria y fiscal, la cual se circunscribe a los objetivos de estabilización cambiaria.

Tal estrategia comercial, más que aumentar la dinámica de acumulación de la economía y de aliviar las presiones sobre el sector externo, empeora tal situación dada nuestra baja competitividad, lo que lleva a la producción nacional a ser desplazada por importaciones y a enfrentar presiones crecientes sobre el sector externo; esto frena la actividad económica y nos hace depender en forma creciente de la entrada de capitales, lo que la coloca en un contexto de alta vulnerabilidad externa.

El TLCAN ha dejado de ser tan atractivo al gran capital internacional como lo fue en un principio debido a que EUA ha firmado acuerdos y convenios comerciales y ha otorgado tratos preferenciales a países que ofrecen mayores atractivos de inversión rentable, ya sea por su infraestructura, por los menores salarios, por la calidad de mano de obra y otras ventajas, lo cual motiva que los flujos de inversión se canalicen hacia ellos y, en consecuencia, México es marginado en dicha asignación porque ha perdido competitividad y atractivo frente a los otros (UNCTAD, 2003). Lo anterior ha llevado a que en la presente década las exportaciones de México a Estados Unidos estén creciendo a menor ritmo

8 El Reporte de la UNCTAD del 2000 nos dice que "cuantas más y más economías en desarrollo optan por estrategias de desarrollo orientadas hacia fuera, la vulnerabilidad de los shocks comerciales y el riesgo de falacia de composición ha sido incrementado" (Trade Development Report 2000, UNCTAD, p. 70). Es decir, el hecho de que le vaya bien a una economía en su estrategia de crecimiento hacia fuera en el momento en que todas las demás economías intenten hacer lo mismo no habrá cabida para todas. 
en comparación con el crecimiento de las importaciones que el país norteamericano realiza con el resto del mundo; por lo tanto, es desplazado en dicho mercado por otros países que tienen mejor competitividad, entre los que sobresale China.

Aquellos países latinoamericanos que están negociando un TLC con EUA y esperan ver incrementado el empleo en sus economías como consecuencia de los mayores flujos de inversión que recibirían como consecuencia de la liberalización económica y de la política que le acompaña no están considerando que los mayores flujos de inversión de Estados Unidos y de los países desarrollados hacia los países en desarrollo van hacia China, por contar este país con menores salarios, mejor infraestructura y un mercado interno con gran potencial. Asimismo, no toman en cuenta que el empleo generado por las empresas de exportación no contrarresta el desempleo originado por el cierre de empresas que se da por su incapacidad competitiva frente a importaciones.

El mayor flujo comercial y de capitales propiciado por la liberalización económica y el proceso de privatización, mas que configurar condiciones productivas, financieras y macroeconómicas para impulsar el crecimiento económico en el país termina atentando contra la esfera productiva, con lo que genera un aumento al déficit de comercio exterior y los requerimientos de entrada de capitales; esto termina frenando la actividad económica, lo que coloca a las economías en un contexto de alta vulnerabilidad externa.

En el siguiente cuadro observamos el creciente déficit de comercio exterior del sector manufacturero sin maquila de México como resultado de la falta de competitividad de la producción nacional frente a importaciones.

\begin{tabular}{lccc}
\hline \multicolumn{4}{c}{$\begin{array}{c}\text { Saldo del comercio exterior del sector manufacturero sin maquila } \\
\text { (millones de dólares) }\end{array}$} \\
\hline Año & Exportaciones & Saldo \\
\hline & & & \\
$\mathbf{1 9 8 8}$ & 12.268 & 18.119 & -5.851 \\
$\mathbf{1 9 8 9}$ & 13.091 & 22.831 & -9.740 \\
$\mathbf{1 9 9 0}$ & 14.860 & 28.831 & -13.663 \\
$\mathbf{1 9 9 1}$ & 16.484 & 35.512 & -19.028 \\
$\mathbf{1 9 9 2}$ & 17.506 & 44.631 & -27.125 \\
$\mathbf{1 9 9 3}$ & 20.650 & 45.710 & -25.060 \\
$\mathbf{1 9 9 4}$ & 24.809 & 54.843 & -30.034 \\
$\mathbf{1 9 9 5}$ & 36.289 & 42.705 & -6.416 \\
$\mathbf{1 9 9 6}$ & 44.105 & 52.970 & $-8,865$ \\
$\mathbf{1 9 9 7}$ & 50.446 & 67.720 & -17.274 \\
$\mathbf{1 9 9 8}$ & 53.467 & 76.276 & -22.809 \\
$\mathbf{1 9 9 9}$ & 59.017 & 85.165 & -26.148 \\
$\mathbf{2 0 0 0}$ & 67.120 & 105.179 & -38.059 \\
$\mathbf{2 0 0 1}$ & 65.355 & 102.742 & -37.387 \\
$\mathbf{2 0 0 2}$ & 65.123 & 101.553 & -36.430 \\
$\mathbf{2 0 0 3}$ & 65.265 & 102.137 & -36.872 \\
$\mathbf{2 0 0 4}$ & 73.113 & 117.423 & -44.310 \\
$\mathbf{2 0 0 5}$ & 70.653 & 110.766 & -40.113 \\
\hline & & & \\
\hline Elaboración propia con base en datos del Banco de México, indicadores económicos $y$ financieros &
\end{tabular}


Esta situación ha afectado al sector manufacturero nacional, lo que se ha traducido en un claro proceso de desindustrialización, tal como se observa en el siguiente cuadro.

\begin{tabular}{|c|c|c|c|c|c|c|c|c|}
\hline Aีn & 1950 & 1960 & 1070 & 1080 & 1000 & 2000 & 2004 & 2005 \\
\hline Panticipación. & 185 & 19.2 & 228 & 23 & 21 & 20 & 18 & 16 \\
\hline
\end{tabular}

Las presiones sobre el sector externo y la menor entrada de capitales obligan al gobierno a mantener sus políticas restrictivas para evitar mayores presiones sobre dicho sector y para generar excedente para cubrir las obligaciones financieras externas. Se paga la deuda con contracción económica y con más deuda, de ahí que la política económica tiene que configurar las condiciones de confianza y rentabilidad exigidas por dicho capital.

En el contexto de políticas restrictivas, menos condiciones endógenas de crecimiento pasa a tener la economía; la liberalización económica pasa a ser insustentable; esto no es estrategia para el crecimiento económico debido a que no genera condiciones endógenas que lo financien, además la colocan en un contexto de alta vulnerabilidad.

Si la economía no cuenta con condiciones productivas y financieras para salir airosa del contexto de liberalización económica y configurar condiciones de crecimiento sostenido, terminará ello por replantear dicha estrategia y anteponer una que priorice el crecimiento hacia el mercado interno, lo cual requiere de política de gasto público, incremento salarial, así como la revisión del contexto de liberalización económica.

Sin embargo, el gobierno mexicano, más que replantear la estrategia actual de crecimiento, plantea profundizar la integración económica con Estados Unidos y Canadá donde los acuerdos energéticos y de movilidad de mano de obra estarían presentes. Estados Unidos está a favor de que se incorporen los acuerdos energéticos, pero no los de inmigración. De ahí los problemas que enfrentan los conciudadanos que no encuentran oportunidades de trabajo bien remuneradas en nuestro país y se ven obligados a cruzar la frontera con Estados Unidos de ilegales en búsqueda de mejores opciones. Cabe señalar que mientras no se modifiquen los tratados comerciales para favorecer la industria nacional y la generación de empleo productivo bien remunerado y no se incorpore en tales tratados la movilidad de mano de obra entre tales países, proseguirán arriesgando la vida en cruzar la frontera aquellos que son excluidos y buscan mejores opciones de vida, a pesar de los muros que Estados Unidos construya en su frontera. 
Por otra parte se habla de crear una unión aduanera común, pero el problema es que ello implica homologar las políticas económicas y ahí hay grandes diferencias; mientras EUA tiene déficit fiscal para impulsar su dinámica económica, México instrumenta una política de disciplina fiscal para disminuir la inflación y estabilizar su moneda. La política monetaria de Estados Unidos es más flexible, al igual que la política cambiaria, a diferencia de México que mantiene una política monetaria restrictiva y un tipo de cambio apreciado. Asimismo, la unión aduanera común implicaría trabajar con una moneda común, que sería el dólar, lo que sería el fin de la política económica para México, pues nosotros no emitimos dólares por lo que dejaríamos de tener política monetaria y de tipo de cambio, así como política fiscal, por lo que no podríamos incidir sobre la actividad económica nacional, pasando a depender ésta de la situación que mantengamos en el sector externo y de los flujos de capital. Asimismo, al presentar la economía nacional un déficit en el sector externo y una alta deuda externa, más se restringiría la actividad económica para poder hacer frente a tal situación en el momento en que no se logren flujos de capital para financiarlos. Si actualmente el país no tiene margen de política económica para el crecimiento, ninguna posibilidad tendría en una unión aduanera.

\section{Conclusión}

Los tratados de libre comercio llevan a la mayoría de las economías del área a depender en forma creciente de la entrada de capitales ante los déficit de comercio exterior manufactureros y la baja dinámica de acumulación que enfrentan, lo que obliga a tener una política económica a favor de la entrada de capitales. De ahí el porqué predominan las políticas de privatización y de estabilidad monetaria, lo que impide tener política económica a favor el crecimiento económico, quedando la economía en función del comportamiento de variables externas.

La mayoría de las economías latinoamericanas no tienen perspectivas de crecimiento hacia el mercado externo, ni de mantener el contexto de apertura comercial generalizada, dado su impacto negativo sobre la esfera productiva, la balanza de comercio exterior y los requerimientos crecientes de entrada de capitales, lo que nos coloca en un contexto de alta vulnerabilidad externa.

En el caso de México, en vez de replantear y revisar los TLC, se quiere profundizar la apertura económica y la mayor integración a la economía de EUA, como si ello viniese a resolver los problemas del país, sin reconocer que tal política ha sido la causa de ellos. 


\section{Bibliografía}

ALBA (2003), "¿Qué es el ALBA?", www.alternativabolivariana.org (consultado: 9 de enero de 2005).

ANDERSON, Kym (2004), "The Challenge of Reducing Subsidies and Trade Barriers", en Policy Research Working Paper, No. 3415, octubre 14, http://econ.worldbank.org (consultado: 12 de diciembre de 2004).

BASTOS, Pedro Paulo Zahluth (2004), "AALCA entre a rodada do Desenvolvimento da OMC e o Regionalismo Unilateral dos EUA", en Economía Política Internacional, No. 2, julio-septiembre, UNICAMP, Sao Paulo, Brasil, www.eco/ unicamp.br/ceri/boletim2.htm (consultado: 10 de enero de 2005).

- (2004), "A Política Comercial Estadounidense: A Estrategia de Liberalização Competitiva, os acordos bilaterais e a ALCA", en Economía Política Internacional, No. 1, abril-junio, UNICAMP, Sao Paulo, Brasil, www.eco/unicamp.br/ceri/boletim1.htm (consultado: 5 de enero de 2005).

BLECKER, Robert (2005), "The North American Economies after NAFTA: A Critical Appraisal", en International Journal of Political Economy.

CALDERÓN, Jorge (2004), "Diez años de TLCAN. Balance Inicial", en Economía Informa, No. 327, Facultad de Economía, UNAM, junio, pp. 48-67.

CASAR, José y Jaime Ros (2004), "¿Por qué no crecemos?", en Nexos, octubre, pp. 57-64.

CEPAL (2004), Oportunidades y retos económicos de China para México y Centro América, Naciones Unidas, septiembre, LC/MEX/L.633

FREUND, Carolina y Orden Cajlar (2004), "Loss Aversión and Trade Policy", en Policy Research Working Paper, No. 3385, septiembre $1^{\circ}$ (econ.worldbank.org).

GAZOL, Antonio (2004), "En torno al agotamiento del TLCAN", en Economía Informa, No. 327, Facultad de Economía, UNAM, junio, pp. 35-41. 
GLAESSNER, Thomas y Daniel Oks (1998), "NAFTA, Capital Mobility and Mexico's Financial System", en Policy Research Working Paper, No. 1984, September 1, World Bank disponible en econ.worldbank.org.

HUERTA, Arturo (2002), Apreciación cambiaria, baja inflación, recesión económica, Diana, México.

HUERTA, Arturo (2004), La economía política del estancamiento, Diana, México.

PUYANA, Jaime y R. González (2004), "Límites y costos del ALCA", en Economía Informa, No. 325, abril, Facultad de Economía, UNAM, pp. 77-90.

RUIZ, Pablo (2004), "El TLCAN y la balanza comercial de México", en Economía Informa, No. 327, junio, Facultad de Economía UNAM, pp. 42-47.

PRESSER, Mario y Ferreira (2004), "Um Breve Guia para o Acordo-Quadro Firmado na OMC em $1^{\circ}$. de Agosto", en Economía Política Internacional, No. 2, jul-sep., UNICAMP, Sao Paulo, Brasil, p.9, www.eco/unicamp.br/ceri/ boletim2.htm (consultado: 10 de enero de 2005).

UNCTAD (1995), Trade Development Report, Naciones Unidas, Nueva York y Ginebra.

UNCTAD (1999), Trade Development Report, Naciones Unidas, Nueva York y Ginebra.

UNCTAD (2003), Trade Development Report, Naciones Unidas, Nueva York y Ginebra.

WILLIAMSON, John (2000), "What Should the World Bank think about the Washington Consensus?", en World Bank Research Observer, Vol. 15, No. 2, August, Washington, D.C. The International Bank for Reconstruction and Development, pp. 251-264. 